\title{
Fabrication of Large-Grain Thick Polycrystalline Silicon Thin Films via Aluminum-Induced Crystallization for Application in Solar Cells
}

\author{
Hsiao-Yeh Chu, ${ }^{1}$ Min-Hang Weng, ${ }^{2}$ and Chen Lin $^{3}$ \\ ${ }^{1}$ Department of Mechanical Engineering, Kun Shan University, Tainan 71003, Taiwan \\ ${ }^{2}$ Metal Industries Research \& Development Center, Kaohsiung 81160, Taiwan \\ ${ }^{3}$ Taiwan Cement Corporation, Taipei 10448, Taiwan \\ Correspondence should be addressed to Hsiao-Yeh Chu; hsiaoyeh@mail.ksu.edu.tw
}

Received 24 December 2012; Revised 27 March 2013; Accepted 29 March 2013

Academic Editor: Ching-Song Jwo

Copyright (c) 2013 Hsiao-Yeh Chu et al. This is an open access article distributed under the Creative Commons Attribution License, which permits unrestricted use, distribution, and reproduction in any medium, provided the original work is properly cited.

The fabrication of large-grain $1.25 \mu \mathrm{m}$ thick polycrystalline silicon (poly-Si) films via two-stage aluminum-induced crystallization (AIC) for application in thin-film solar cells is reported. The induced $250 \mathrm{~nm}$ thick poly-Si film in the first stage is used as the seed layer for the crystallization of a $1 \mu \mathrm{m}$ thick amorphous silicon (a-Si) film in the second stage. The annealing temperatures in the two stages are both $500^{\circ} \mathrm{C}$. The effect of annealing time (15,30,60, and 120 minutes) in the second stage on the crystallization of a-Si film is investigated using X-ray diffraction (XRD), scanning electron microscopy, and Raman spectroscopy. XRD and Raman results confirm that the induced poly-Si films are induced by the proposed process.

\section{Introduction}

Silicon thin films can reduce the cost of solar cells and associated consumption of pure silicon. Polycrystalline silicon (poly-Si) film is a promising material for solar cell application because its carrier mobility is 10 to 100 times larger than that of a hydrogenated amorphous silicon (a-Si:H) film [1]. Three methods are currently used for manufacturing polySi film on glass: catalytic chemical vapor deposition [2], excimer laser annealing (ELA) [3], and metal-induced crystallization (MIC) [4-10]. Aluminum-induced crystallization (AIC) induces the crystallization of a-Si below the eutectic temperature $\left(577^{\circ} \mathrm{C}\right)$ of $\mathrm{Al}$ and $\mathrm{Si}$. Therefore, it can be effectively applied to large-area glass substrates at process temperatures below the glass transformation temperature [ 4 , 5]. In addition, AIC can create poly-Si film with a lateral grain size that is larger than the film thickness [5]. However, commonly studied poly-Si films often have a thickness of below $500 \mathrm{~nm}$ [6-10], which is insufficient for the active layer of solar cells. For example, Hossain et al. [9] fabricated poly-Si films with a lateral grain size of up to $20 \mu \mathrm{m}$, but the film thickness was as low as $300 \mathrm{~nm}$. Subramanian et al. [10] fabricated a poly-Si film via two-step solid-phase crystallization. The process temperature was as high as $700^{\circ} \mathrm{C}$. The grain size and film thickness were $350 \mathrm{~nm}$ and $100 \mathrm{~nm}$, respectively. Two-step AIC was used in the study of Tüzün et al. [11]. However, their process temperature was as high as $1160^{\circ} \mathrm{C}$

In this work, $1.25 \mu \mathrm{m}$ thick large-grain poly-Si films are fabricated via a two-stage AIC method. The process temperature is $500^{\circ} \mathrm{C}$, which is below the glass transformation temperature.

\section{Experiments}

Figure 1 shows the experimental procedure of the two-stage annealing for fabricating thick poly-Si films. The substrate material is a wafer. The standard RCA cleaning process was applied before film deposition. In order to simulate a glass substrate and prevent the crystal orientation of the wafer substrate from affecting the crystallization of the a-Si:H layer [9], a $200 \mathrm{~nm}$ thick $\mathrm{SiO}_{2}$ film was deposited over the wafer surface in a wet oxide tube using atmospheric-pressure 


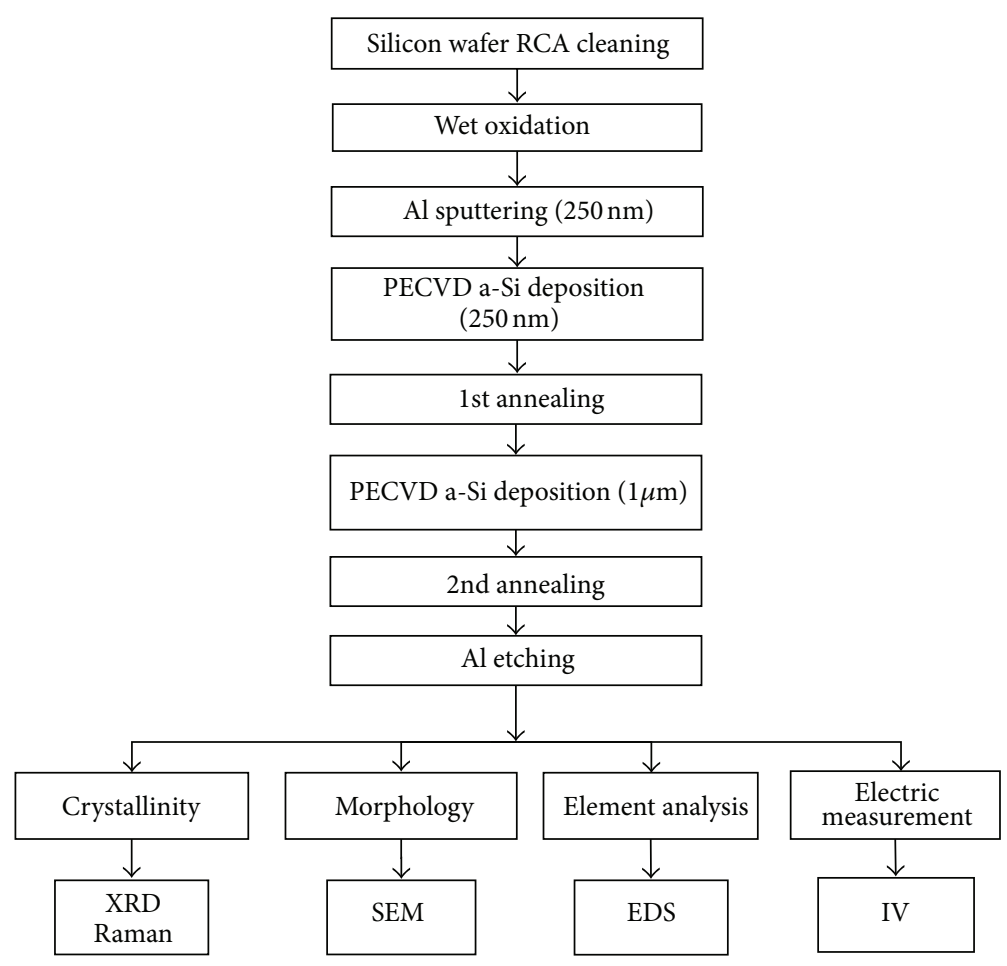

FIGURE 1: Flow chart of experimental procedure.

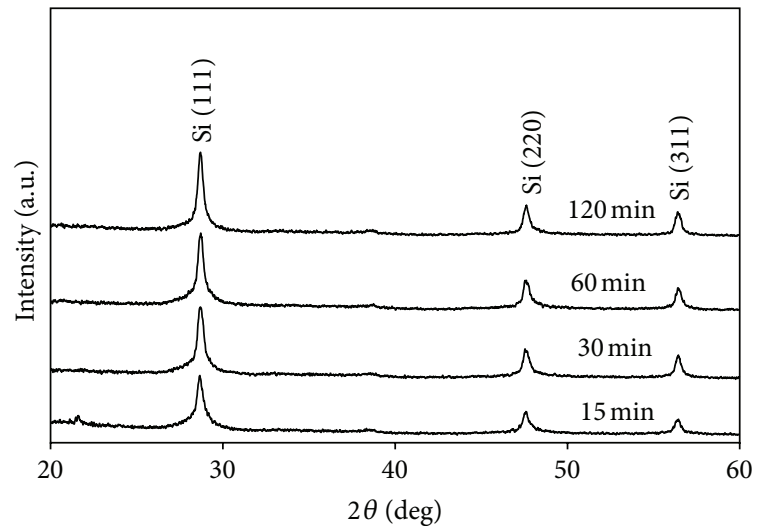

FIGURE 2: XRD patterns of specimens annealed for various durations.

chemical vapor deposition (APCVD). Then, an aluminum film was deposited on the top surface of the $\mathrm{SiO}_{2}$ film by sputtering. A layer of a-Si film was then deposited on top of the Al film using plasma-enhanced chemical vapor deposition (PECVD). The specimen was then annealed at $500^{\circ} \mathrm{C}$ for 1 hour at a nitrogen flow rate of $2 \mathrm{slm}$ in the first stage of annealing.

After the first annealing process, a $1 \mu \mathrm{m}$ thick a-Si film was deposited by PECVD. The specimens were then annealed at $500^{\circ} \mathrm{C}$ for $15,30,60$, and 120 minutes, respectively. The specimens were then wet-etched in order to remove the residual aluminum content.

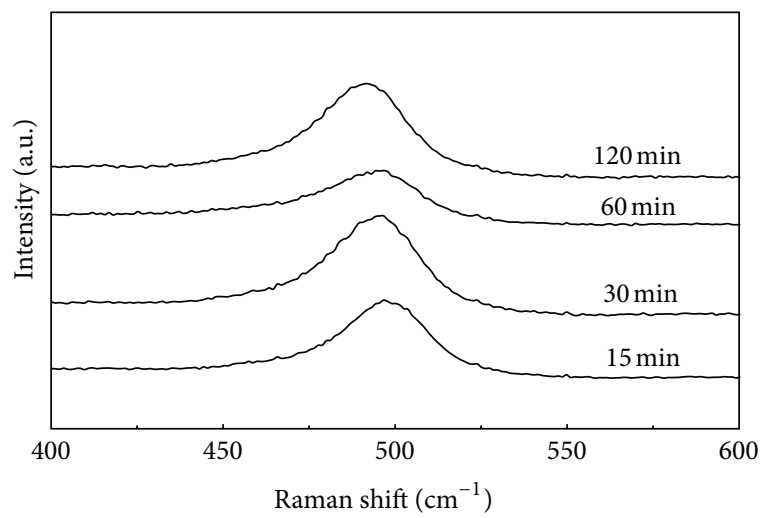

FIGURE 3: Raman spectra of specimens annealed for various durations.

X-ray diffraction (XRD, Rigaku RINT 2000) and Raman spectroscopy (TRIAX 550) were used to evaluate the crystallinity of the induced poly-Si film. Scanning electron microscopy (SEM, Philips XL-40FEG) was used to observe the morphology of the film surface and cross section. The leakage current density of the induced poly-Si thin film was measured to evaluate the film quality.

\section{Results and Discussion}

Figure 2 shows the XRD patterns of the induced poly-Si films after the second annealing process. Three silicon peaks, corresponding to Si (111), (220), and (311), respectively, appear 


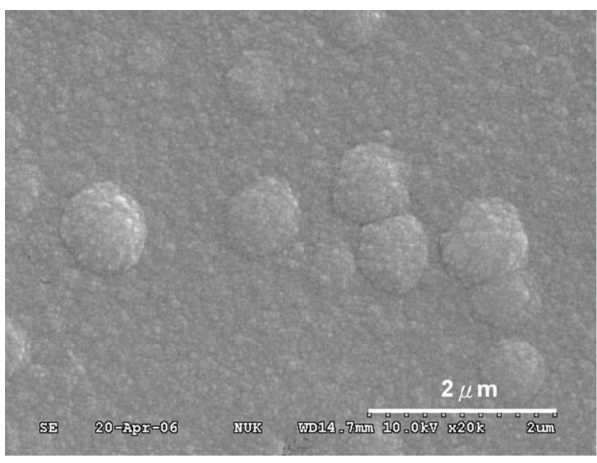

(a)

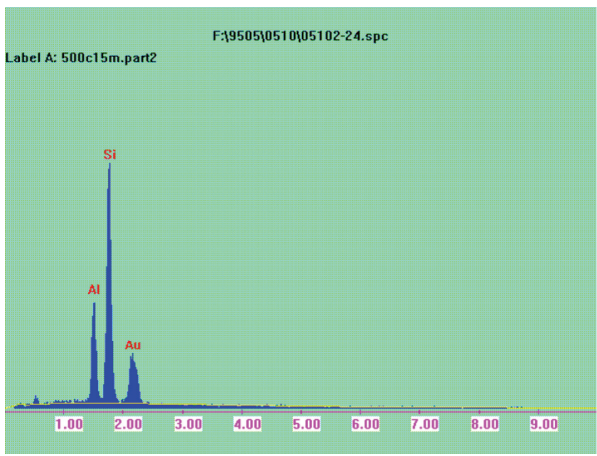

(c)

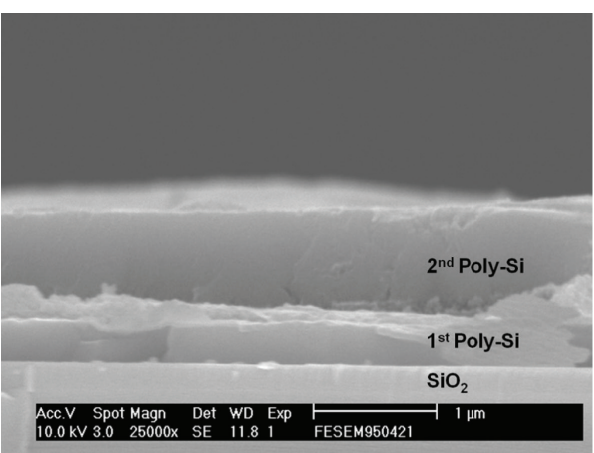

(e)

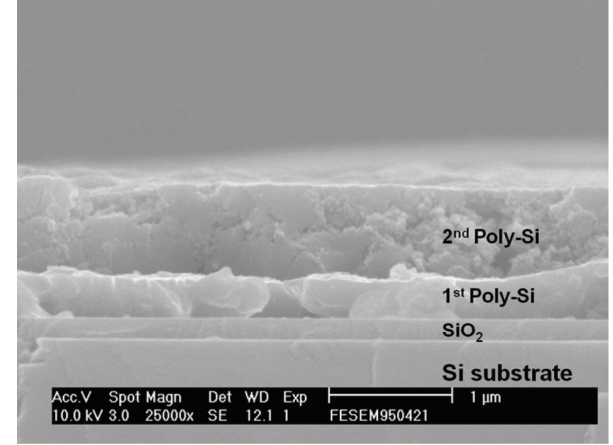

(b)

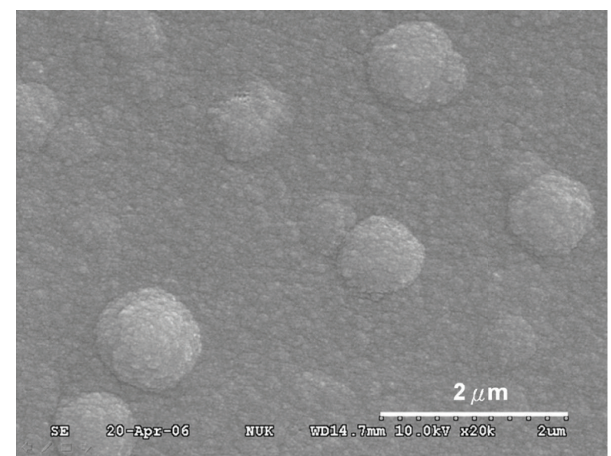

(d)

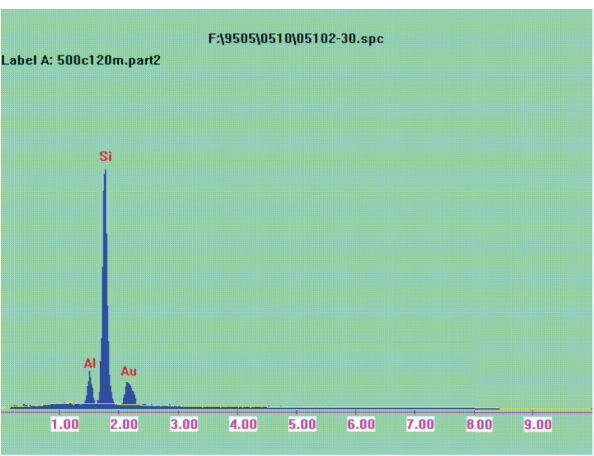

(f)

FIGURE 4: SEM images and EDS results of induced poly-Si thin films annealed for various durations: (a) 15 min, top view; (b) 15 min, crosssectional view; (c) $15 \mathrm{~min}$, EDS results; (d) $120 \mathrm{~min}$, top view; (e) $120 \mathrm{~min}$, cross-sectional view; and (f) 120 min, EDS results.

for all samples, confirming that poly-Si film was successfully induced in each case. No Si (100)-related peaks were detected in any specimen even though a $\mathrm{Si}(100)$ wafer was used as the substrate. This is due to the glancing angle being very small $\left(1^{\circ}\right)$ during the XRD measurement and the $200 \mathrm{~nm}$ thick $\mathrm{SiO}_{2}$ film being sufficiently thick to prevent $\mathrm{X}$-rays from reaching the $\mathrm{Si}(100)$ wafer substrate [10]. Note that there is a fairly small peak at around $2 \theta=39^{\circ}$ that corresponds to $\mathrm{Al}$ (111) for all specimens in Figure 2. This indicates that $\mathrm{Al}$ had not been completely etched off even though selective Al etching was conducted on the surface of the crystallized Si film. The peak intensity increases with annealing time, but eventually levels off, indicating that a second-stage annealing time of over 120 minutes will not further increase the crystalline silicon intensity.
Raman spectra measurements were performed on the induced poly-Si thin films after the second stage to confirm crystallinity. The results are shown in Figure 3. The maximum-intensity peaks of the Raman shift are located between 492 and $497 \mathrm{~cm}^{-1}$. This result verifies that poly-Si films were induced.

Figure 4 shows SEM images of the top surface and cross section of the induced poly-Si thin films after the two-stage annealing AIC process. Figures 4(a) and 4(d) show that the circular grain size of the poly-Si film is about $1 \sim 2 \mu \mathrm{m}$. The grain size increases with increasing annealing time. The energy-dispersive spectrometer (EDS) results in Figures 4(c) and 4(f) show that the $\mathrm{Al}$ residue intensity decreases with increasing the annealing time. It indicates that the $\mathrm{Al}$ precipitation from the seed layer increases with increasing 


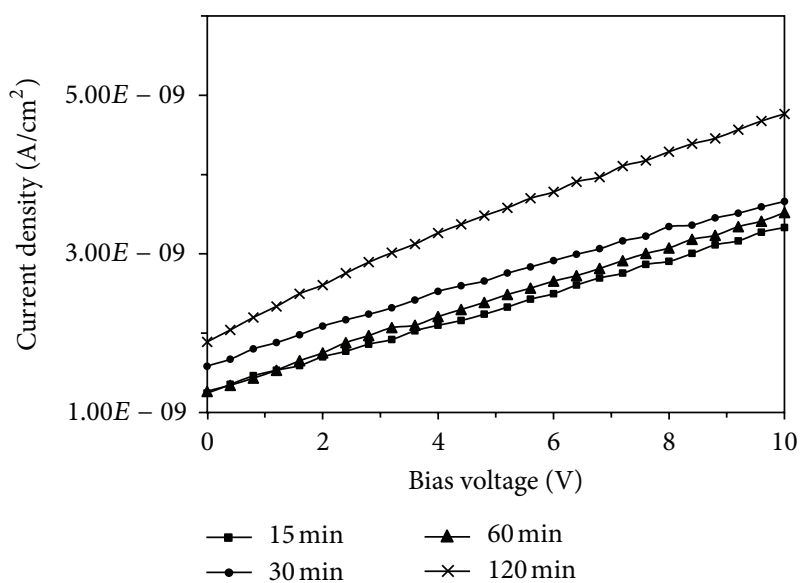

FIGURE 5: Leakage current densities of the induced poly-Si thin films annealed under four different annealing time periods.

the annealing time. The cross-sectional SEM images in Figure 4 clearly show the first and second layers of the induced poly-Si. The lateral grain size is larger than the film thickness.

Figure 5 shows the leakage current densities of the induced poly-Si thin films. The leakage current density slightly increases with increasing annealing time. The leakage current densities for all induced poly-Si thin films are below $5 \times 10^{-9} \mathrm{~A} / \mathrm{cm}^{2}$, indicating that the induced films have good quality without many defects or serious grain boundary effect [10].

\section{Conclusion}

A thick large-grain poly-Si film for application in solar cells was fabricated via AIC. The overall thickness of the poly-Si film was about $1.25 \mu \mathrm{m}$. XRD patterns and Raman spectra confirmed that the poly-Si film was induced using the proposed process at $500^{\circ} \mathrm{C}$.

\section{Acknowledgments}

This work was supported by National Nano Device Laboratories, Taiwan, under Project NDL 94S-C046. The authors also would like to thank Professor Ru-Yuan Yang in the Graduate Institute of Materials Engineering, National Ping-Tung University of Science and Technology. A lot of materials analyses were finished in Professor Yang's labs.

\section{References}

[1] S. W. Lee, Y. C. Jeon, and S. K. Joo, "Pd induced lateral crystallization of amorphous Si thin films," Applied Physics Letters, vol. 66, no. 13, pp. 1671-1673, 1995.

[2] O. Ebil, R. Aparicio, S. Hazra, R. W. Birkmire, and E. Sutter, "Deposition and structural characterization of poly-Si thin films on Al-coated glass substrates using hot-wire chemical vapor deposition," Thin Solid Films, vol. 430, no. 1-2, pp. 120$124,2003$.
[3] F. M. Zhang, X. C. Liu, G. Ni, and Y. W. Du, "Controlled growth of high-quality poly-silicon thin films with huge grains on glass substrates using an excimer laser," Journal of Crystal Growth, vol. 260, no. 1-2, pp. 102-108, 2004.

[4] J. Schneider, R. Heimburger, J. Klein, M. Muske, S. Gall, and W. Fuhs, "Aluminum-induced crystallization of amorphous silicon: influence of temperature profiles," Thin Solid Films, vol. 487, no. 1-2, pp. 107-112, 2005.

[5] M. Shahidul Haque, H. A. Naseem, and W. D. Brown, "Interaction of aluminum with hydrogenated amorphous silicon at low temperatures," Journal of Applied Physics, vol. 75, no. 8, pp. 3928-3935, 1994.

[6] M. S. Ashtikar and G. L. Sharma, "Structural investigation of gold induced crystallization in hydrogenated amorphous silicon thin films," Japanese Journal of Applied Physics, vol. 34, no. 10, pp. 5520-5526, 1995.

[7] H. Kim, G. Lee, D. Kim, and S. H. Lee, "A study of polycrystalline silicon thin films as a seed layer in liquid phase epitaxy using aluminum-induced crystallization," Current Applied Physics, vol. 2, no. 1, pp. 129-133, 2002.

[8] P. I. Widenborg and A. G. Aberle, "Surface morphology of polySi films made by aluminium-induced crystallisation on glass substrates," Journal of Crystal Growth, vol. 242, no. 3-4, pp. 270$282,2002$.

[9] M. Hossain, H. M. Meyer, H. H. Abu-Safe, H. Naseem, and W. D. Brown, "Large-grain poly-crystalline silicon thin films prepared by aluminum-induced crystallization of sputter-deposited hydrogenated amorphous silicon," Journal of Materials Research, vol. 21, no. 3, pp. 761-766, 2006.

[10] V. Subramanian, P. Dankoski, L. Degertekin, B. T. Khuri-Yakub, and K. C. Saraswat, "Controlled two-step solid-phase crystallization for high-performance polysilicon TFT's," IEEE Electron Device Letters, vol. 18, no. 8, pp. 378-381, 1997.

[11] Ö. Tüzün, A. Slaoui, I. Gordon et al., "N-type polycrystalline silicon films formed on alumina by aluminium induced crystallization and overdoping," Thin Solid Films, vol. 516, no. 20, pp. 6892-6895, 2008. 

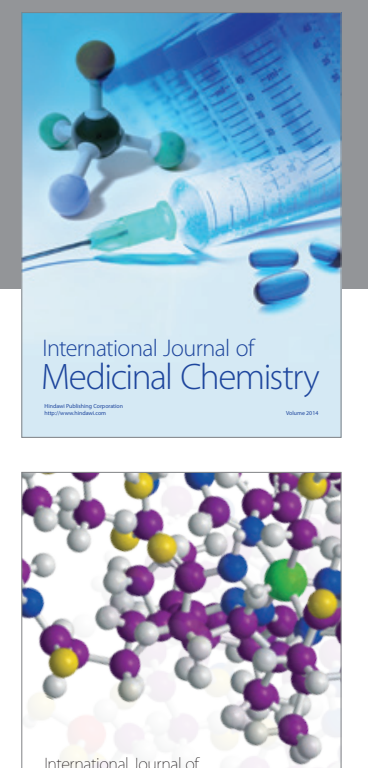

\section{Carbohydrate} Chemistry

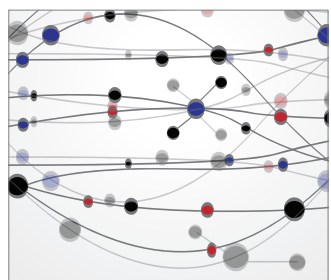

The Scientific World Journal
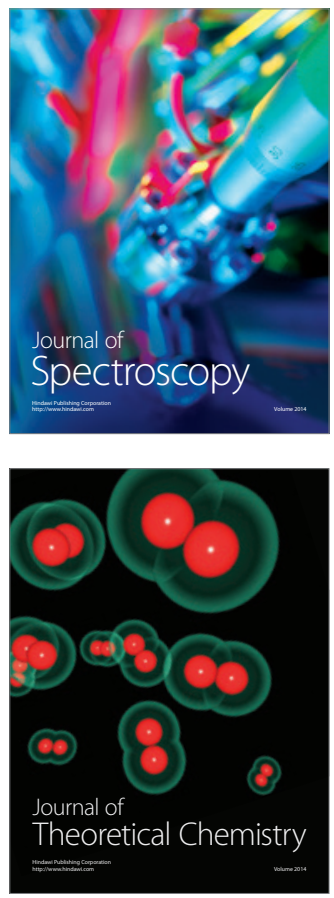
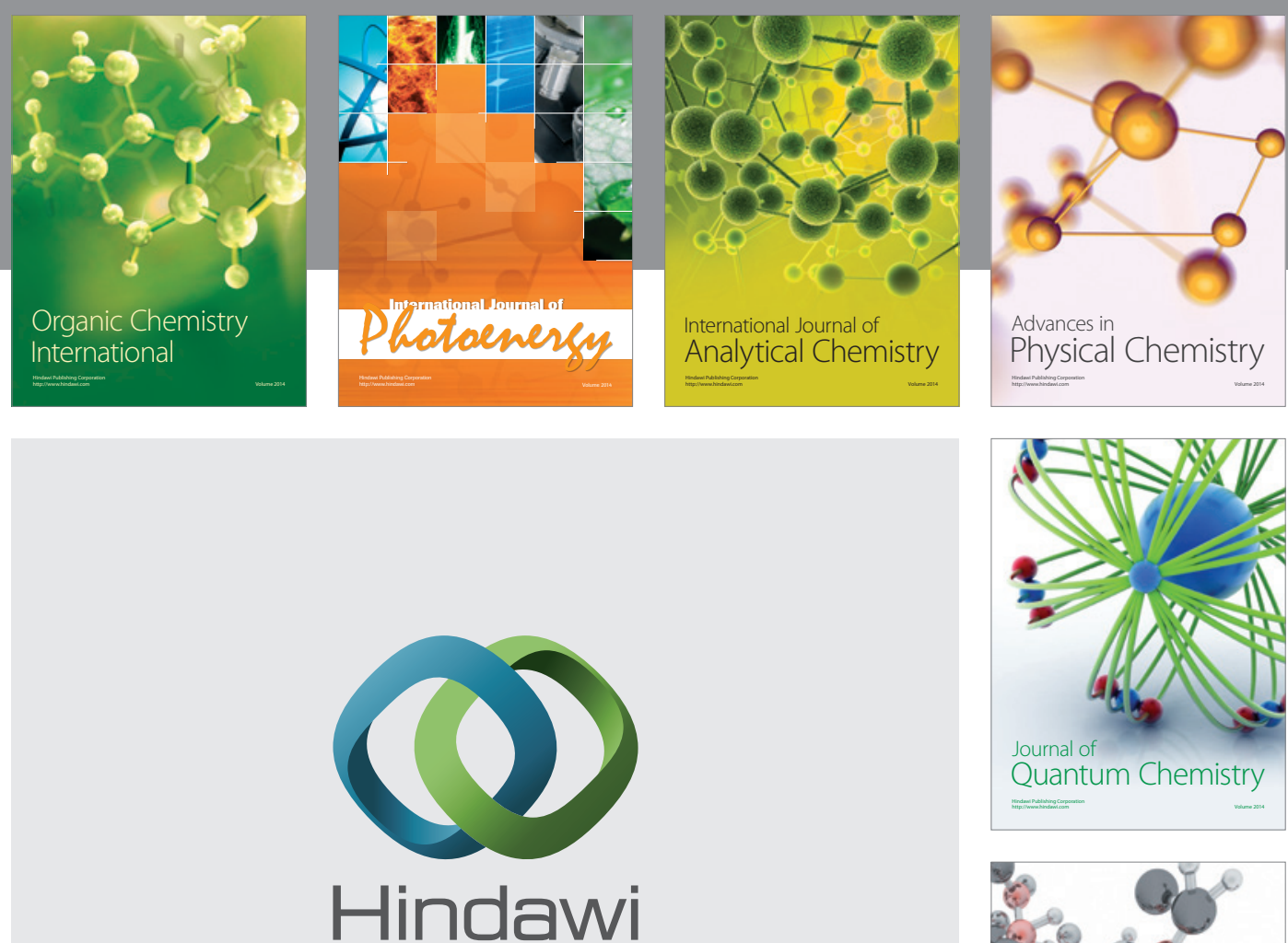

Submit your manuscripts at

http://www.hindawi.com

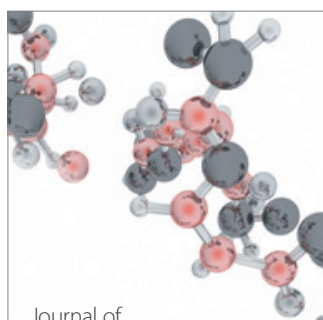

Analytical Methods

in Chemistry

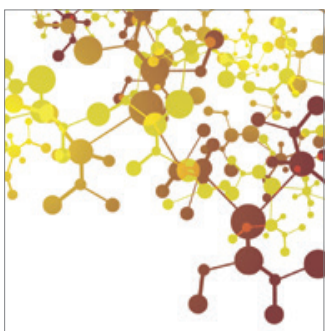

Journal of

Applied Chemistry

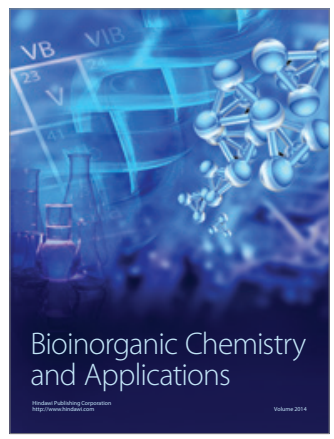

Inorganic Chemistry
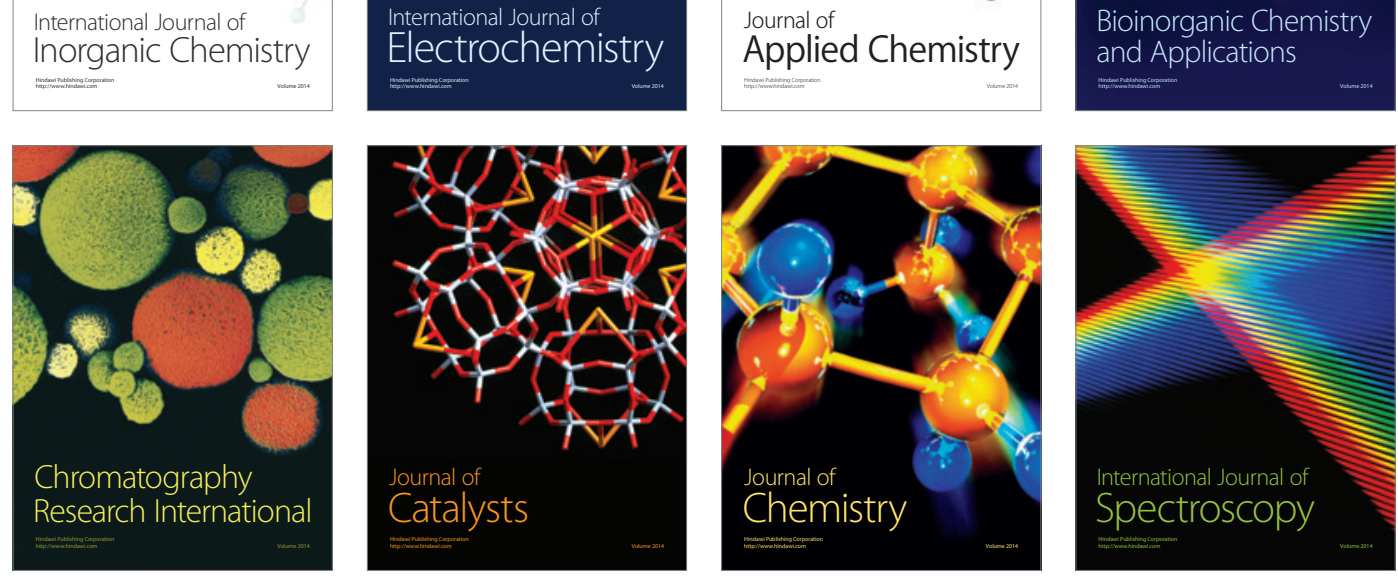